\title{
Dermoscopic signs of lichen planus
}

\author{
Noureddine Litaiem, Yasmine Mansour, Mariem Jones, Faten Zeglaoui
}

Department of Dermatology, Charles Nicolle Hospital, University Tunis El Manar, Tunis, Tunisia

\section{Correspondence to} Dr Noureddine Litaiem, noureddine.litaiem@gmail.com

Accepted 19 December 2015

\section{DESCRIPTION}

A 55-year-old woman presented with a 3-month history of violaceous, itchy, flat-topped papules located on her forearms (figure 1), trunk and legs. There was no history of drug intake.

The forearm lesions were studied with a handheld dermoscope $(\delta 10$; Heine Optotechnik, Germany) revealing yellow dots and Wickham striae (WS), surrounded by radial linear and dotted capillaries (figure 2). Mature lesions also revealed peripheral pigmented dots and diffuse scale distribution (figure 3). The diagnosis of lichen planus (LP) was considered after clinical and dermoscopic correlation, and confirmed histologically. Screening for hepatitis B and C was negative.

Dermoscopy is a non-invasive tool widely used in the diagnosis of skin tumours. ${ }^{1}$ Recently, its applicability also extended to the field of inflammatory skin disorders. ${ }^{2}$ LP is an idiopathic inflammatory disease of the skin and mucous membranes. Our report highlights the main characteristics of active LP. Vascular structures are the earliest dermoscopic signs of LP.

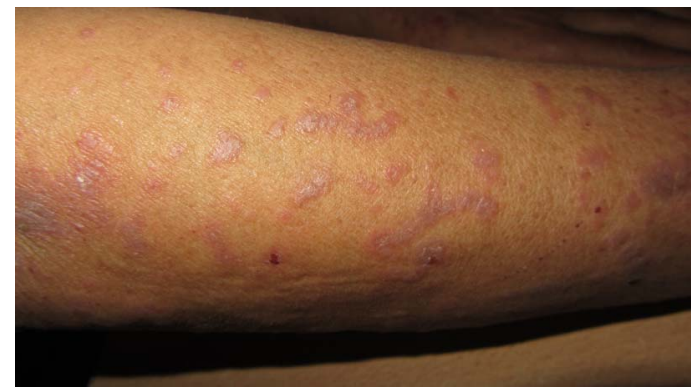

Figure 1 Clinical presentation of active lichen planus. Purplish-violaceous, polygonal-shaped, flat-topped small papules located on the forearms. The surface is slightly shiny showing a network of fine white lines ('Wickham's striae'). Coalescence into linear plaques is related to Koebner phenomenon. Excoriations are also present.

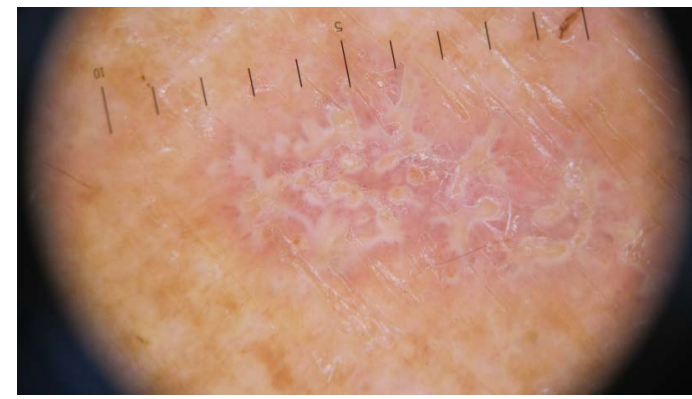

Mansour $\mathrm{Y}$, Jones $\mathrm{M}$, et al BMJ Case Rep Published online: [please include Day Month Year] doi:10.1136/ bcr-2015-213923
Figure 2 Dermoscopy of a recent papule shows yellow dots, and reticular pearly whitish and yellowish structures that correspond to the Wickham striae, surrounded by radial linear and dotted capillaries.

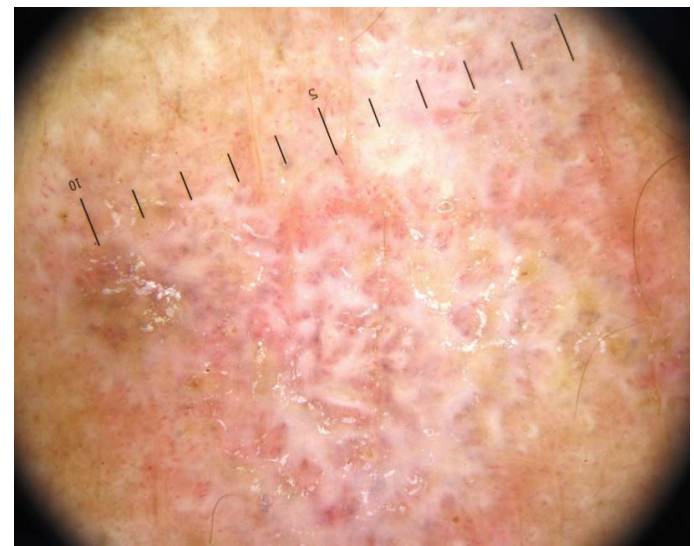

Figure 3 Dermoscopy of a mature papule revealing Wickham striae, peripheral dotted and radial linear capillaries, peripheral pigmented dots and diffuse scales.

WS is the hallmark sign of LP and corresponds histologically to focal thickening of the granular layer. Several WS patterns have been described including circular, reticular, radial linear, globular, perpendicular and veil-like structureless forms. ${ }^{1}{ }_{2}$ WS are mainly seen in the active stages and disappear after treatment, thus their presence could be considered as an activation marker. ${ }^{1}$

Deep dotted hyperpigmentation is related to pigment in dermal melanophages and resists treatment.

Dermoscopic features of LP may be of precious aid to the clinical diagnosis, especially in discriminating between LP and lichenoid sarcoidosis, ${ }^{3}$ psoriasis, dermatitis and pityriasis rosea. ${ }^{2}$ It could also help early detection of treatment response.

\section{Learning points}

- Dermoscopy contributes to the early diagnosis of lichen planus (LP). Dermoscopic signs of active LP include Wickham striae (WS), vascular structures (especially red dots, radial capillaries) and hyperpigmentation (brownish diffuse or deeper dotted patterns).

- WS are considered pathognomonic of LP. However, their absence should not exclude the diagnosis. WS could be missing especially in treated LP or in particular forms of LP (LP pigmentosus, actinic LP).

- Dermoscopy could be useful for the evaluation of treatment outcome in patients with LP, as vascular structures and WS tend to disappear under appropriate treatment. However, deep dotted pigmentation corresponds to the presence of pigment in dermal melanophages and is typically resistant to treatment. 
Contributors NL wrote the first draft of the manuscript. YM managed the literature searches and analyses. MJ and FZ revised the manuscript. All the authors contributed to and have approved the final manuscript.

Competing interests None declared.

Patient consent Obtained.

Provenance and peer review Not commissioned; externally peer reviewed.

\section{REFERENCES}

1 Güngör \$̧, Topal IO, Göncü EK. Dermoscopic patterns in active and regressive lichen planus and lichen planus variants: a morphological study. Dermatol Pract Concept 2015;5:45-53.

2 Lallas A, Kyrgidis A, Tzellos TG, et al. Accuracy of dermoscopic criteria for the diagnosis of psoriasis, dermatitis, lichen planus and pityriasis rosea. $\mathrm{Br} I$ Dermatol 2012;166:1198-205.

3 Vazquez-Lopez F, Palacios-Garcia L, Gomez-Diez S, et al. Dermoscopy for discriminating between lichenoid sarcoidosis and lichen planus. Arch Dermatol 2011;147:1130.

Copyright 2016 BMJ Publishing Group. All rights reserved. For permission to reuse any of this content visit http://group.bmj.com/group/rights-licensing/permissions.

BMJ Case Report Fellows may re-use this article for personal use and teaching without any further permission.

Become a Fellow of BMJ Case Reports today and you can:

- Submit as many cases as you like

- Enjoy fast sympathetic peer review and rapid publication of accepted articles

- Access all the published articles

- Re-use any of the published material for personal use and teaching without further permission

For information on Institutional Fellowships contact consortiasales@bmjgroup.com

Visit casereports.bmj.com for more articles like this and to become a Fellow 